\title{
Predictors of risk of alcohol-exposed pregnancies among women in an urban and a rural area of South Africa
}

\author{
Neo K. Morojele ${ }^{\mathrm{a}, *}$, Leslie London ${ }^{\mathrm{b}}$, Steve A. Olorunju ${ }^{\mathrm{c}}$, Maila J. Matjila ${ }^{\mathrm{d}}$, Adlai S. Davids ${ }^{\mathrm{e}}$, \\ Kirstie M. Rendall-Mkosi ${ }^{\mathrm{d}}$ \\ a Medical Research Council, Pretoria, Gauteng, South Africa \\ ${ }^{\mathrm{b}}$ School of Public Health and Family Medicine, University of Cape Town, South Africa \\ ${ }^{\mathrm{c}}$ Biostatistics Unit, Medical Research Council, Pretoria, Gauteng, South Africa \\ ${ }^{\mathrm{d}}$ School of Health Systems and Public Health, University of Pretoria, South Africa \\ ${ }^{\mathrm{e}}$ Social Aspects of HIV/AIDS and Health, Human Sciences Research Council, Port Elizabeth, South Africa
}

\section{A R T I C L E I N F O}

\section{Article history:}

Available online $\mathrm{xxx}$

\section{Keywords:}

South Africa

Fetal Alcohol Syndrome

Alcohol-exposed pregnancy

Alcohol consumption

Contraception

Women

\begin{abstract}
A B S T R A C $T$
The study sought to determine the prevalence and predictors of being at risk of an alcohol-exposed pregnancy (AEP) among women of child-bearing age in an urban and rural location in South Africa. We conducted a cross-sectional household survey of 1018 women aged 18-44 years in one urban $(n=606)$ and one rural $(n=412)$ site. The women were interviewed using a structured questionnaire. We defined the primary dependent variable, being at risk of having an AEP, as current alcohol use, not being pregnant, being fertile, and no effective use of contraceptives. The independent variables included demographic, substance use, health perceptions, psycho-social, and partner characteristics. The rural women (21.84\%) were more likely than their urban counterparts (11.22\%) to be at risk of an AEP. In multiple logistic regression analyses, significant predictors of being in the "at risk" group for the urban women were (a) being 'white' as opposed to 'black/African', and being 'coloured' as opposed to 'black/African'; and (b) current smoking. For the rural women, significant risk factors were (a) current smoking and (b) early onset of alcohol use. The significant protective factors were (a) education; (b) knowledge about Fetal Alcohol Syndrome; (c) parity. Use of stricter alcohol use criteria (i.e., three or more drinks and five or more drinks per sitting) in the definition of risk of an AEP yielded slightly different patterns of significant predictors. The results revealed high levels of risk of an alcohol-exposed pregnancy, especially amongst the rural women, and a need for location-specific prevention programmes. The high burden of AEP in South Africa calls for the establishment of national AEP prevention strategies and programmes as a matter of urgency.
\end{abstract}

(c) 2009 Elsevier Ltd. All rights reserved.

\section{Main text}

Alcohol misuse is a preventable cause of adverse reproductive and pregnancy outcomes, including Fetal Alcohol Spectrum Disorders (FASDs). Fetal Alcohol Syndrome (FAS) is the most recognised form of FASD, with other variants being Partial Fetal Alcohol Syndrome (PFAS), Alcohol-Related Birth Defects (ARBD), and Alcohol-Related Neuro-Developmental Disorder (ARND; Stratton, Howe, \& Battaglis, 1996).

The highest global rates of FAS and PFAS have been identified in various regions of South Africa since the mid-1980s, and most notably, in rural farming areas in the Western Cape Province (May et al., 2000, 2007; Palmer, 1985; Viljoen et al., 2005; te Water Naude, London, Pitt, \& Mahomed, 1998). More recent studies,

\footnotetext{
* Corresponding author. Tel.: +27 12339 8535; fax: +27 123398594 .

E-mail address: neo.morojele@mrc.ac.za (N.K. Morojele).
}

conducted in high risk areas of the Northern Cape (Urban et al., 2008) and Gauteng provinces (Viljoen, Craig, Hymbaugh, Boyle, \& Blount, 2003), have also documented high rates. Of concern are the observed increases in the prevalence of FAS; studies among three separate cohorts of Grade 1 pupils in Western Cape province in 1997 (May et al., 2000), 1999 (Viljoen et al., 2005), and 2001 (May et al., 2007) identified rates of FAS of $40.5-46.4$ per $1000 ; 65.2-74.2$ per 1000; and $68.0-89.0$ per 1000 , respectively. The rate of FAS identified in an urban area of Gauteng province was 19 per 1000 (Viljoen et al., 2003), whereas a combined rate for two locations in the Northern Cape of 67.2 per 1000 was identified between 2001 and 2004 (Urban et al., 2008).

Episodic binge drinking characterises alcohol consumption among many populations in southern Africa (WHO, 2004). In South Africa, levels of problem drinking among women who consume alcohol are relatively high and not appreciably different from those of men (Parry et al., 2005). Binge alcohol consumption is of concern 
for women since it has been identified as particularly harmful to the unborn child (Maier \& West, 2001).

Programmes to reduce levels of FAS are required specifically to minimise women's risk of having an alcohol-exposed pregnancy (AEP) by virtue of being of child-bearing age, fertile, consumers of alcohol, and non-users or ineffective users of contraceptives. However, research in South Africa to date has not identified factors associated with women's increased risk of having an AEP. In South Africa, social norms favouring fertility and childbearing (Wood \& Jewkes, 2006); barriers to attendance of and access to family planning clinics (Stephenson, Baschieri, Clements, Hennink, \& Madise, 2007); and a lack of accurate and complete information about how to use contraceptives effectively (Beksinska, Rees, Nkonyane, \& McIntyre, 1998) are among factors that prevent contraceptive use.

Maternal risk factors for FAS have been investigated in the Western and Northern Cape provinces (May et al., 2005, 2008; Urban et al., 2008; Viljoen, Croxford, Gossage, Kodituwakku, \& May, 2002). The risk factors identified by those studies include: (1) demographic characteristics (e.g., education, occupation/employment, income, marital status at index pregnancy); (2) alcohol consumption patterns (e.g., current drinking, age of onset of drinking); (3) tobacco use behaviours (e.g., tobacco use during pregnancy); (4) partners' and family members' characteristics (e.g., partner drinking, heavy drinking by family members); (5) alcohol consumption prior to and during each month of the past pregnancy; (6) reproductive health history (e.g., parity, gravidity, birth order of index child, stillbirth); (7) physical characteristics (e.g., height, weight and body mass index; BMI). Religiosity was identified as a protective factor. These maternal risk and protective factors for FAS are not dissimilar to the factors associated with being at risk of an AEP that have been identified in other parts of the world (Mengel, Searight, \& Cook, 2006; Project Choices Research Group, 2002).

South Africa has yet to develop a comprehensive strategy to reduce AEPs. Knowledge of the risk and protective factors for having an AEP is particularly useful for informing policy and public health intervention programmes for preventing AEPs (Floyd, Ebrahim, Boyle, \& Gould, 1999). Thus far, population-based studies on AEPs have not been conducted in South Africa. To fill this gap, this study was conducted among women aged 18-44 years in two comparison sites: a densely populated urban area of Gauteng province and a sparsely populated rural farming area of the Western Cape Province. The aims of the study were to determine, for each site separately: (a) the extent to which women of childbearing age are at risk of having an AEP and (b) the demographic, health, substance use, psycho-social, community, and partner predictors of risk for having an AEP among women of child-bearing age. This study was designed as part of the formative phase of an intervention programme designed to apply a public health approach to preventing AEP that would include universal, indicated and selective interventions (May, 1995).

\section{Method}

We conducted a cross-sectional survey in two sites in 2006. Although the survey is not nationally representative, it covers two contrasting geographical areas. The research was approved by the Faculty of Health Sciences Research Ethics Committees of the Universities of Pretoria (121/2005) and Cape Town (381/2005).

\section{Sample selection}

Urban site

The urban study site is located within the City of Tshwane Metropolitan Municipality which is in the highly industrialised and urbanised province of Gauteng (Statistics South Africa, 2003). According to 2005 population estimates provided by Human Sciences Research Council (2006), the study site has just over 340,000 residents comprising 'white' (14.1\%), 'coloured' (7.4\%), and 'black/African' (78.3\%) people. Alcohol is widely available through legal and illegal outlets, and alcohol consumption is becoming increasingly normative for women in areas such as these.

We used a cluster random sampling approach with a goal of recruiting 820 women participants in this site. First, we randomly selected 82 census enumeration areas; then from each area, we randomly selected 10 households using aerial photographs to identify households within the selected areas; finally, we randomly selected one eligible woman (i.e., 18-44 years) within each selected household and invited her to participate in the study.

\section{Rural site}

The rural site is in the Western Cape province and borders the Atlantic Ocean on the west and agricultural land on the east. The study area spans three local municipalities of the West Coast District Municipality: Cederberg, Bergrivier and Swartland. The combined population of the three municipalities, based on the 2001 population census, is just under 160,000, and Afrikaansspeaking people of mixed heritage (referred to as "coloured" in South Africa) make up the majority of the population (West Coast District Municipality, 2009). Agriculture, forestry and fishing are major contributors to the economy of the region (Urban-Econ, 2006). The now abolished dop system, which involved part payment of farm workers in low-grade wine, promoted excessive alcohol use among this region's farming communities and such patterns of alcohol consumption still prevail (London, 1999).

In this site (spanning three municipal areas), we used a stratified cluster random sampling approach with a target of recruiting 650 women as participants. First, we chose farms within the boundaries of the selected areas, with a probability proportional to the number of farms in each municipality. From a total set of 1450 farms across the 3 municipalities, we randomly selected 150 farms, with oversampling to take account of un-contactable, ineligible, and nonfunctional farms. Finally, we approached all eligible women (18-44 years) in every household within each of the participating farms $(n=58)$ to participate in the study; we included all eligible women per farm due to the small average number of households per farm (approximately seven) and the large distances between farms.

\section{Survey administration}

Trained fieldworkers visited the selected households and used a structured questionnaire to conduct face-to-face interviews with eligible women in their chosen language. Those who provided informed consent were interviewed. The interviews were conducted at the participants' homes and lasted for between 15 and $90 \mathrm{~min}$. On completion, each woman was given a resource and fact sheet with information about alcohol-exposed pregnancies and contact details of local alcohol counselling and treatment as well as family planning services.

\section{Measures}

We used a structured questionnaire which included, as far as possible, questionnaire measures that have been used among similar populations in South Africa. The questionnaire had questions to assess demographic characteristics, substance use, contraceptive use and reproductive health factors for characterising the sample. The demographic questions assessed the women's age, education, marital status, socio-economic status (SES), current employment status, and socially classified racial group (SCRG; King, 
1997), which we refer to in this article as 'race' and which in South Africa is based on the apartheid construct which classified people as 'white', 'coloured', 'black/African' and 'Indian'. We present further details about the measurement of the demographic variables in the section on the independent variables below.

Alcohol use questions relevant to this paper included measures of lifetime and current alcohol use, and the 10-item Alcohol Use Disorders Identification Test (AUDIT; Babor, Higgins-Biddle, Saunders, \& Monteiro, 2001). Tobacco use questions concerned lifetime, current and regular (lifetime use of at least 100 cigarettes) use of cigarettes.

Questionnaire measures also assessed the women's lifetime, current and effective use of contraceptives. The reproductive health measures assessed the women's current pregnancy and fertility status.

\section{Dependent variables}

We examined three dependent variables that corresponded to three levels of risk of an alcohol-exposed pregnancy: Level 1 applied to women who met the following four criteria: (a) were not pregnant at the time of the interview; (b) were fertile; (c) had drunk alcohol during the past 30 days; (d) were not using any form of contraceptive or were using an ineffective method of contraceptive (e.g., calendar/rhythm method, withdrawal method, traditional herbs/remedies) at the time of the study. Those who met all four criteria had a score of ' 1 ', while those who did not meet all four criteria were assigned a score of ' 0 ' on this variable. This first definition of risk of an AEP discounted the frequency and quantity of alcohol consumed since evidence on a threshold level of alcohol intake during pregnancy that is harmful is inconclusive (Jacobson \& Jacobson, 1994; Sampson, Streissguth, Bookstein, \& Barr, 2000). Level 2, a more stringent definition of risk of an AEP, required women to meet all of the above criteria and to also report typically drinking at least three drinks per occasion. Those who met all five criteria had a score of ' 1 ', while those who did not meet all five criteria were assigned a score of ' 0 ' on this variable. Level 3 , the most stringent definition, required women to report typically drinking five or more drinks per occasion as well as meeting all other criteria. Those who met all five criteria had a score of ' 1 ', while those who did not meet all five criteria were assigned a score of ' 0 ' on this variable.

\section{Independent variables}

The independent variables were measured by mostly binary scales and assessed variables within six domains: (a) socio-demographic factors; (b) health perceptions; (c) substance use; (d) psycho-social factors; (e) community factors; (f) partner characteristics.

Socio-demographic factors. We categorised age into three age groups: 18-24 years, 25-34 years and 35-44 years, respectively. Since the results of our analyses using age as a continuous variable and as a categorical variable were similar, we used the categorical variable for ease of interpretation of the results. We dichotomised educational status into primary schooling or lower, versus above primary education. We dichotomised parity as more than one child (1) versus one or no children (0). We categorised marital status as married (legally and traditionally) or cohabiting, versus not married/cohabiting. We asked participants to self-identify according to the 'race' groups of 'black/African', 'coloured', "white", and "Asian/Indian". We defined unemployment as not currently being in any form of employment. We assigned participants who reported possession of five or more out of eight household assets and commodities (electricity, a radio, a television, a telephone, a fridge, a computer, a washing machine and a cellular telephone) a high socio-economic status (SES) score (1), and those reporting less than five were assigned a low SES score (0).

Health perceptions. We included one 4 -item health perceptions scale and one 5-item mental health scale based on the Short-Form20 Health Survey (Stewart, Hays, \& Ware, 1988). We dichotomised each scale, as per Stewart's scoring instructions, and for each measure, we assigned those with low functioning on the scale a score of " 1 ", while all others were assigned a score of " 0 ".

Substance use. We categorised participants who indicated having smoked cigarettes during the past 30 days as current smokers. Women who reported ever having used cannabis were categorised as cannabis users. We assigned a score of " 1 " to those who reported having first drunk alcohol before the age of 18 years, while all others were assigned a score of " 0 " on the variable "alcohol use onset as a minor". This variable was originally continuous, but we subsequently categorised it, as it was severely skewed for both the urban and rural sites.

Psycho-social factors. The psycho-social variables included selfesteem, knowledge about FAS, religious involvement, male entitlement and perceptions about cultural prescriptions on childbearing. We summed and dichotomised scores on the 10 -item Rosenberg (1965) self-esteem scale across the 75th percentile to denote high versus low self-esteem. We assessed participants' knowledge of the risks of drinking during pregnancy (FAS knowledge) by asking whether alcohol consumption during pregnancy affects the unborn foetus, with responses coded as " 0 " for those responding "no", and "1" for all other responses. Scores on a 6 -item religious orientation scale (Idehen, 2001) were summed, and dichotomised into high and low religiosity split at the 75th percentile. Using a single-item scale we assessed participants' extent of agreement that their culture entitles males to have as many children as they wish to, and we assigned a score of " 1 " to those who strongly or moderately agreed, and to all others we assigned a score of " 0 " on this measure. We used a single-item scale to assess participants' belief that their culture prescribed a childbearing obligation to women, and we assigned a score of " 1 " to those who agreed, and a score of "0" to those who did not agree.

Community factors. To assess access to recreational facilities, we asked participants to indicate on a single-item 5-point Likert scale, their extent of agreement or disagreement with the statement "You can easily use the recreational facilities in your community". We assigned a score of " 1 " to those who indicated high access to recreational facilities (by strongly or moderately agreeing with the statement), while those who neither agreed nor disagreed, or moderately disagreed, or strongly disagreed were assigned a score of " 0 ". We used a single-item Likert scale to assess participants' perceived access to alcohol by asking how strongly they agreed or disagreed with the statement, "It is easy for you to buy alcohol in your community if you want to"; those who strongly and moderately agreed were assigned a score of " 1 ", while those who neither agreed nor disagreed, moderately disagreed, or strongly disagreed were assigned a score of " 0 ". We summed and dichotomised across the 75th percentile, scores on a 6-item social capital scale (Martin, Rogers, Cook, \& Joseph, 2004), into weak (0) versus strong (1) social capital.

Partner characteristics. We created a variable, 'older partner', for those who had a partner aged 30 years or older $($ score $=1)$ versus those with a partner younger than 30 years $($ score $=0$ ). We categorised the women's partners' educational status around Grade 8: those with a partner educated beyond Grade 8 were assigned 
a score of " 1 ", and those whose partners had Grade 8 or lower were assigned a " 0 " on this scale. We created a variable for bingeing partner for those with a partner who engaged in binge drinking (i.e., they drank six or more drinks per occasion; score $=1$ ) versus those whose partner did not binge drink or those without a partner $($ score $=0)$.

\section{Statistical analyses}

We first calculated the percentages of women who reported various levels of alcohol use, contraception and being at risk of an AEP (Levels 1, 2 and 3). We then used logistic regression analysis to determine whether there were significant bivariate associations between each predictor and each of the three dependent variables. This was followed by using forced multiple logistic regression analysis and entering all those independent variables that had a significant $(p<0.05)$ pair wise relationship with the dependent variable in the bivariate analysis. To take into account our sampling approaches, we adjusted for the clustering effect in the urban site. We adjusted for the clustering twice in the rural site (farms and households), and we also adjusted for the strata, i.e., the three municipalities. Since the results of the analyses following the adjustments did not differ appreciably from the results without the adjustments, we present the non-adjusted results in this paper. The initial logistic regression analyses were conducted using SPSS, and we used STATA procedure, Proc SVY psu, to adjust for the clustering. The logistic regression analyses results are reported first, for Level 1, i.e., the least strict dependent variable, followed by Level 2 , followed by Level 3 . Reduced statistical power limits the reliability of the results of the regression analyses particularly for the Level 3 outcome. Multiple logistic regression analyses were not conducted to predict the Level 3 outcome in the urban site because very few women (i.e., 15/606) met the criteria.

\section{Results}

We received completed questionnaires from $83 \%$ of the rural women and $74 \%$ of the urban women who were approached to participate in the study. The participation rate was low (29\%) among potential respondents in the urban area who would identify themselves on 'race' as 'white'.

Demographic factors, alcohol use, contraception prevalence and risk of $A E P$

The mean ages of the urban and rural women were 30.2 years and 31.0 years, respectively. Significant differences between women in the two sites were observed for all demographic factors except for age (Table 1 ).

Overall, $72 \%$ of the rural women and $40 \%$ of the urban women reported lifetime alcohol use (Table 1 ). The rural women were also more likely than their urban counterparts to report current alcohol consumption, harmful/hazardous drinking (AUDIT score of 8 or more), and lifetime, current and regular smoking. However, there were no significant differences in rates of lifetime, current or ineffective contraceptive use, or pregnancy or infertility at the time of the interviews.

Overall, $11.22 \%$ of the urban women and $21.84 \%$ of the rural women met Level 1 criteria for being at risk of an AEP. For Level 2 criteria, $6.44 \%$ of the urban women and $16.75 \%$ of the rural women qualified as being at risk. In total, $2.48 \%$ of the urban women and $8.50 \%$ of the rural women qualified as being at risk of an AEP according to the strictest definition. Table 1 shows percentages of urban and rural women who were at Level 1 risk of an AEP, broken down by their demographic, substance use and reproductive health
Table 1

Demographic, substance use, contraceptive use and reproductive health characteristics of participants.

\begin{tabular}{|c|c|c|c|c|c|}
\hline & \multirow{2}{*}{\multicolumn{2}{|c|}{$\begin{array}{l}\text { Urban site Rural site } \\
(N=606) \%(N=412) \%\end{array}$}} & \multirow{2}{*}{$p^{\mathrm{a}}$} & \multicolumn{2}{|c|}{ At Level 1 risk of AEP } \\
\hline & & & & $\begin{array}{l}\text { Urban site } \\
(N=606) \%\end{array}$ & $\begin{array}{l}\text { Rural site } \\
(N=412) \%\end{array}$ \\
\hline \multicolumn{6}{|l|}{ Age (years) } \\
\hline $18-24$ & 30.0 & 24.8 & & 11.5 & 21.6 \\
\hline $25-34$ & 38.0 & 39.1 & & 8.7 & 20.5 \\
\hline $35-44$ & 32.0 & 36.2 & 0.151 & 14.4 & 23.5 \\
\hline \multicolumn{6}{|l|}{ Education } \\
\hline$<$ Grade 11 & 28.1 & 92.2 & & 8.8 & 22.2 \\
\hline Grade $11-12$ & 57.3 & 7.1 & & 12.4 & 13.8 \\
\hline Further studies ${ }^{\mathrm{b}}$ & 14.6 & 0.7 & $<0.001$ & 12.5 & 33.3 \\
\hline \multicolumn{6}{|l|}{ Marital status } \\
\hline Married $^{\mathrm{c}}$ & 30.6 & 30.8 & & 10.3 & 15.7 \\
\hline Living with partner ${ }^{d}$ & 6.0 & 34.7 & & 5.6 & 24.5 \\
\hline Never married & 58.7 & 30.3 & & 10.4 & 25.6 \\
\hline $\begin{array}{l}\text { Divorced/separated/ } \\
\text { widow }\end{array}$ & 4.8 & 4.1 & $<0.001$ & 37.9 & 17.6 \\
\hline \multicolumn{6}{|l|}{ 'Race’' } \\
\hline 'Black/African' & 81.4 & 8.5 & & 6.1 & 11.4 \\
\hline ‘Coloured' & 11.1 & 90.8 & & 37.3 & 22.8 \\
\hline 'White' & 7.5 & 0.7 & $<0.001$ & 31.1 & 33.3 \\
\hline \multicolumn{6}{|l|}{ Employment status } \\
\hline Unemployed & 58.1 & 19.9 & & 8.5 & 15.9 \\
\hline $\begin{array}{l}\text { Employed part-time/ } \\
\text { self-employed }\end{array}$ & 16.4 & 35.9 & & 14.1 & 22.3 \\
\hline Employed full-time & 25.5 & 44.2 & $<0.001$ & 16.2 & 24.2 \\
\hline \multicolumn{6}{|l|}{ Socio-economic status } \\
\hline $\begin{array}{l}\text { Five or more } \\
\text { amenities }\end{array}$ & 66.4 & 35.9 & $<0.001$ & 13.9 & 15.0 \\
\hline \multicolumn{6}{|l|}{ Alcohol consumption } \\
\hline Lifetime use & 40.3 & 72.3 & $<0.001$ & 28.3 & 30.2 \\
\hline Use & 20.1 & 41.3 & $<0.001$ & 57.0 & 52.9 \\
\hline $\begin{array}{l}\text { Harmful/hazardous } \\
\text { drinking }^{\mathrm{d}}\end{array}$ & 7.6 & 32.8 & $<0.001$ & 45.7 & 49.6 \\
\hline \multicolumn{6}{|l|}{ Cigarette use } \\
\hline Lifetime use & 19.0 & 69.7 & $<0.001$ & 32.2 & 25.4 \\
\hline Current use & 9.2 & 57.3 & $<0.001$ & 37.9 & 28.2 \\
\hline Regular use $\mathrm{e}^{\mathrm{e}}$ & 8.9 & 48.1 & $<0.001$ & 35.7 & 24.2 \\
\hline \multicolumn{6}{|l|}{ Contraceptive use } \\
\hline Lifetime use & 58.4 & 51.7 & 0.066 & 6.5 & 8.5 \\
\hline Current use & 51.2 & 44.9 & 0.089 & 2.9 & 0.0 \\
\hline Effective use & 43.9 & 44.7 & 0.859 & 0.0 & 0.0 \\
\hline \multicolumn{6}{|l|}{ Reproductive health } \\
\hline Pregnant currently & 4.8 & 3.2 & 0.261 & 0.0 & 0.0 \\
\hline Infertile/sterilised & 2.1 & 1.0 & 0.246 & 0.0 & 0.0 \\
\hline
\end{tabular}

characteristics. Similar figures for Levels 2 and 3 can be obtained from the authors.

\section{Predictors of risk of AEP}

\section{Urban site}

Bivariate logistic regression analyses revealed that the urban women who were at significantly greater risk of having an AEP selfidentified as 'white' $(\mathrm{OR}=9.15 ; 95 \% \mathrm{CI}=4.93-16.96 ; p<0.001)$ or 'coloured' $(\mathrm{OR}=6.94 ; 95 \% \mathrm{CI}=3.34-14.42 ; p<0.001)$ as opposed to 'black/African'; were of higher socio-economic status ( $\mathrm{OR}=2.53$; $95 \% \mathrm{CI}=1.32-4.85 ; p<0.01)$; were current smokers $(\mathrm{OR}=6.51$; $95 \% \mathrm{CI}=3.54-11.98 ; p<0.001)$; had ever used cannabis $(\mathrm{OR}=4.01$; 
$95 \% \mathrm{CI}=1.66-9.68 ; p<0.01)$; had initiated alcohol before 18 years $(\mathrm{OR}=3.62 ; 95 \% \mathrm{CI}=1.98-6.61 ; p<0.001)$; and perceived recreational facilities to be highly accessible $(\mathrm{OR}=2.28 ; 95 \% \mathrm{CI}=1.38$ 3.79; $p<0.001)$. Those at significantly less risk of AEP were unemployed $(\mathrm{OR}=0.51 ; 95 \% \mathrm{CI}=0.31-0.85 ; p<0.01)$; and agreed that males were entitled to father as many children as they desired $(\mathrm{OR}=0.41 ; 95 \% \mathrm{CI}=0.22-0.74 ; p<0.01)$. After entering the eight variables which were significantly $(p<0.05)$ associated with the dependent variable into a forced multivariate logistic regression model, 'race' and current smoking emerged as independently associated with risk of AEP (Table 2).

Bivariate logistic regression analyses predicting Level 2 AEP risk identified six significant risk factors, namely, 'race' ('white' versus 'black/African': $\mathrm{OR}=6.56 ; 95 \% \mathrm{CI}=3.11-13.84 ; p<0.001$; and 'coloured' versus 'black/African': $\mathrm{OR}=3.82 ; 95 \% \mathrm{CI}=1.44-10.12$; $p<0.01)$; SES $(\mathrm{OR}=2.35 ; 95 \% \mathrm{CI}=1.02-5.43 ; p<0.05)$, current smoking ( $\mathrm{OR}=5.80 ; 95 \% \mathrm{CI}=2.79-12.06 ; p<0.001)$; alcohol use onset as a minor ( $\mathrm{OR}=3.90 ; 95 \% \mathrm{CI}=1.88-8.11 ; p<0.001)$; selfesteem ( $\mathrm{OR}=2.14 ; 95 \% \mathrm{CI}=1.10-4.17 ; p<0.05)$; and access to recreational facilities ( $\mathrm{OR}=3.32 ; 95 \% \mathrm{CI}=1.71-6.44 ; p<0.001)$. There were two protective factors: parity $(\mathrm{OR}=0.32 ; 95 \%$ $\mathrm{CI}=0.22-0.87 ; p<0.05)$ and religiosity $(\mathrm{OR}=0.21 ; 95 \% \mathrm{CI}=0.06-$ $0.68 ; p<0.01)$. In a multivariate analysis, the significant and independent predictors of Level 2 AEP risk were current smoker status; high self-esteem; high access to recreational facilities; and low religiosity (Table 2 ).

The significant bivariate predictors of Level 3 risk of AEP were being 'white' as opposed to 'black/African' ( $\mathrm{OR}=4.87$; $95 \% \mathrm{CI}=1.54-15.35 ; p<0.01$ ); current smoking ( $\mathrm{OR}=5.08 ; 95 \%$ $\mathrm{CI}=1.67-15.40 ; \quad p<0.01)$; lifetime cannabis use $(\mathrm{OR}=6.47$; $95 \% \mathrm{CI}=1.70-24.57 ; p<0.01)$ onset of drinking as a minor $(\mathrm{OR}=7.3395 \% \mathrm{CI}=2.57-20.90 ; p<0.001)$; and better access to

Table 2

Results of multivariate logistic regression analyses predicting risk of alcohol-exposed pregnancy (AEP): urban site.

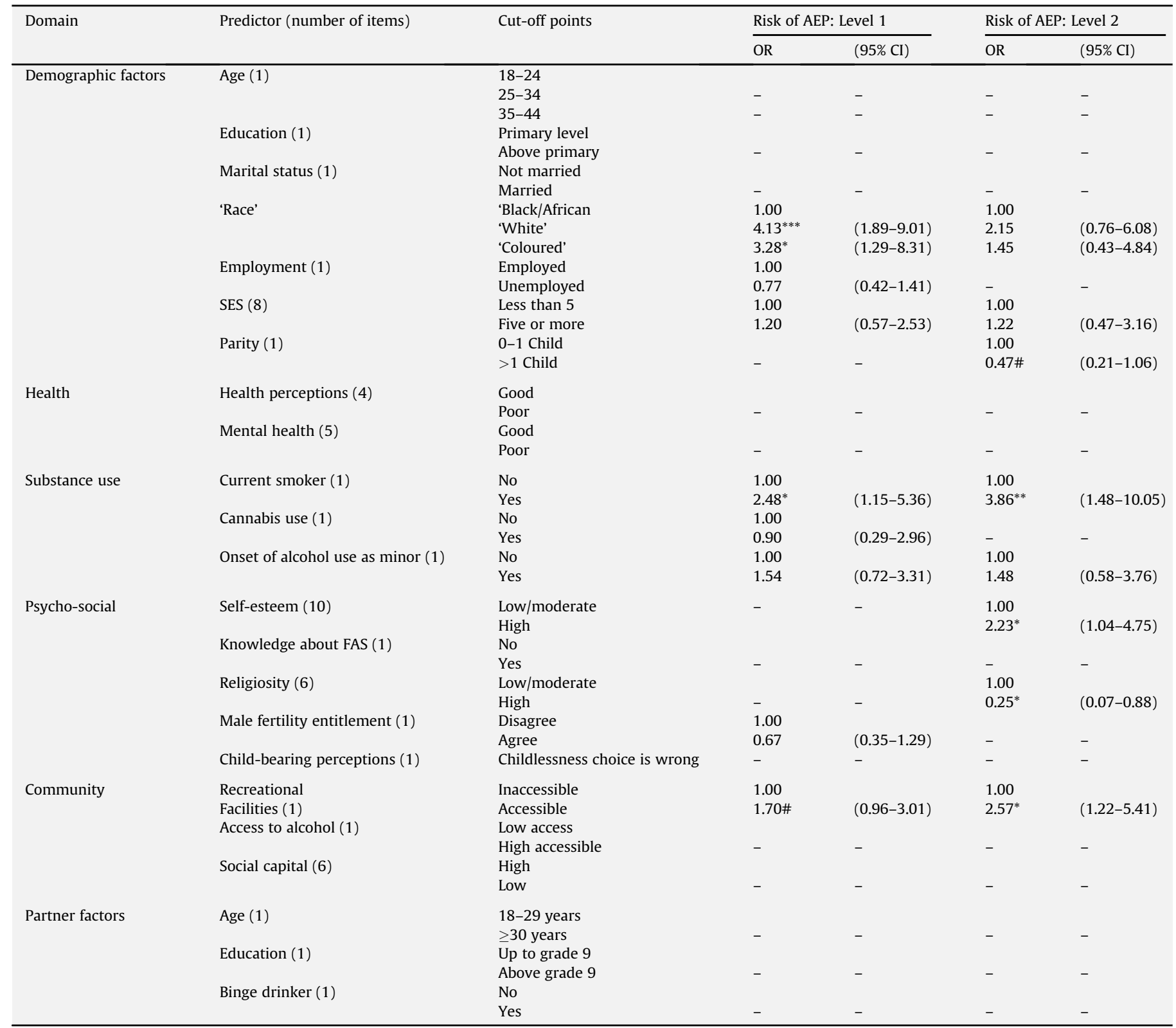

${ }^{*} p<0.05 ;{ }^{* *} p<0.01 ;{ }^{* * *} p<0.001 ; \# p<0.10$. - : Variable not included in multivariate analysis.

Note: multivariate analyses were not conducted for the Level 3 risk of AEP dependent variable for this site due to sample size limitations. 
recreational facilities $(\mathrm{OR}=3.28 ; 95 \% \mathrm{CI}=1.15-9.36 ; p<0.05)$. Less risk was associated with parity $(\mathrm{OR}=0.07 ; 95 \% \mathrm{CI}=0.09-0.54$; $p<0.01$ ). Results of multivariate analyses are not reported due to insufficient numbers of participants in the risk group (i.e., 15).

\section{Rural site}

For the rural women, greater risk of an AEP using Level 1 criteria was significantly associated with current smoking ( $O R=2.73 ; 95 \%$ $\mathrm{CI}=1.60-4.66 ; p<0.001$ ); alcohol use onset prior to age 18 years $(\mathrm{OR}=2.52 ; 95 \% \mathrm{CI}=1.55-4.09 ; p<0.001)$; and having a binge drinking partner $(\mathrm{OR}=1.84 ; 95 \% \mathrm{CI}=1.15-2.95 ; p<0.05)$. Less risk of an AEP was significantly associated with more than a primary education ( $\mathrm{OR}=0.57 ; 95 \% \mathrm{CI}=0.34-0.94 ; p<0.05)$; higher socioeconomic status ( $\mathrm{OR}=0.50 ; 95 \% \mathrm{CI}=0.30-0.86 ; p<0.05)$; higher parity $(\mathrm{OR}=0.46 ; 95 \% \mathrm{CI}=0.29-0.74 ; p<0.01)$; high self-esteem $(\mathrm{OR}=0.55 ; \quad 95 \% \quad \mathrm{CI}=0.31-0.95 ; \quad p<0.05) ; \quad$ FAS knowledge $(\mathrm{OR}=0.50 ; 95 \% \mathrm{CI}=0.29-0.86 ; p<0.05)$, and high religiosity
$(\mathrm{OR}=0.48 ; 95 \% \mathrm{CI}=0.27-0.85 ; p<0.05)$. In the multivariate logistic regression analysis, two risk factors (current smoking and onset of alcohol use before age 18 years) and three protective factors (education, FAS knowledge, and parity) retained significance (Table 3).

The bivariate analyses using the Level 2 definition of risk of AEP revealed the following significant risk factors: current smoking $(\mathrm{OR}=2.87 ; 95 \% \mathrm{CI}=1.56-5.28 ; p<0.01)$; alcohol onset as a minor $(\mathrm{OR}=2.16 ; 95 \% \mathrm{CI}=1.27-3.67 ; p<0.01)$; and partner binge drinking $(\mathrm{OR}=2.10 ; 95 \% \mathrm{CI}=1.24-3.58 ; p<0.01)$. The protective factors were higher education $(\mathrm{OR}=0.47 ; 95 \% \mathrm{CI}=0.26-0.84$; $p<0.05$ ); parity ( $\mathrm{OR}=0.49 ; 95 \% \mathrm{CI}=0.29-0.82 ; p<0.01$ ); selfesteem ( $\mathrm{OR}=0.50 ; 95 \% \mathrm{CI}=0.27-0.94 ; p<0.05)$; and religiosity $(\mathrm{OR}=0.50 ; 95 \% \mathrm{CI}=0.26-0.95 ; p<0.05)$. Two protective factors (education and parity) and one risk factor (current smoker) remained significantly and independently associated with the outcome in the multivariate analysis (Table 3 ).

Table 3

Results of multivariate logistic regression analyses predicting risk of alcohol-exposed pregnancy (AEP): rural site.

\begin{tabular}{|c|c|c|c|c|c|c|c|c|}
\hline \multirow[t]{2}{*}{ Domain } & \multirow[t]{2}{*}{ Predictor (number of items): } & \multirow[t]{2}{*}{ Cut-off points } & \multicolumn{2}{|c|}{ Risk of AEP: Level 1} & \multicolumn{2}{|c|}{ Risk of AEP: Level 2} & \multicolumn{2}{|c|}{ Risk of AEP: Level 3} \\
\hline & & & OR & $(95 \% \mathrm{CI})$ & OR & $(95 \% \mathrm{CI})$ & OR & $(95 \% \mathrm{CI})$ \\
\hline \multirow[t]{15}{*}{ Demographic factors } & Age (1) & $18-24$ & - & - & - & - & 1.00 & \\
\hline & & $25-34$ & - & - & - & - & 0.49 & $(0.18-1.33)$ \\
\hline & & $35-44$ & - & - & - & - & 0.72 & $(0.27-1.96)$ \\
\hline & Education (1) & Primary Level & 1.00 & & 1.00 & & & \\
\hline & & Above primary & $0.53^{*}$ & $(0.30-0.94)$ & $0.48^{*}$ & $(0.25-0.91)$ & - & - \\
\hline & Marital status (1) & Not married & & & & & & \\
\hline & & Married & - & - & - & - & - & - \\
\hline & Race (1) & Black/African & & & & & & \\
\hline & & ‘Coloured’ & - & - & - & - & - & - \\
\hline & Employment (1) & Employed & & & & & & \\
\hline & & Unemployed & - & - & - & - & - & - \\
\hline & SES (8) & Less than 5 & 1.00 & & & & & \\
\hline & & Five or more & 0.76 & $(0.41-1.42)$ & - & - & - & - \\
\hline & Parity (1) & 0-1 Child & 1.00 & & $1.00^{*}$ & & 1.00 & \\
\hline & & $>1$ Child & $0.42^{* *}$ & $(0.24-0.73)$ & $0.36^{*}$ & $(0.20-0.67)$ & 0.50 & $(0.21-1.20)$ \\
\hline \multirow[t]{4}{*}{ Health } & Health perceptions (4) & Good & & & & & & \\
\hline & & Poor & - & - & - & - & - & - \\
\hline & Mental health (5) & Good & & & & & & \\
\hline & & Poor & - & - & - & - & - & - \\
\hline \multirow[t]{6}{*}{ Substance Use } & Current smoker (1) & No & 1.00 & & 1.00 & & 1.00 & \\
\hline & & Yes & $1.85^{*}$ & $(1.02-3.37)$ & $1.96^{*}$ & $(1.01-3.80)$ & $2.92^{*}$ & $(1.10-7.79)$ \\
\hline & Cannabis use (1) & No & & & & & 1.00 & \\
\hline & & Yes & - & - & - & - & 2.48 & $(0.78-7.93)$ \\
\hline & Onset of alcohol use as minor (1) & No & 1.00 & & 1.00 & & 1.00 & \\
\hline & & Yes & $2.04^{*}$ & $(1.16-3.59)$ & 1.37 & $(0.75-2.50)$ & $2.25^{*}$ & $(1.03-4.89)$ \\
\hline \multirow[t]{9}{*}{ Psycho-social } & Self-esteem (10) & Low/moderate & 1.00 & & 1.00 & & & \\
\hline & & High & 0.67 & $(0.36-1.22)$ & $0.52 \#$ & $(0.27-1.03)$ & - & - \\
\hline & Knowledge about FAS (1) & No & 1.00 & & & & & \\
\hline & & Yes & $0.37^{* *}$ & $(0.20-0.70)$ & - & - & - & - \\
\hline & Religiosity (6) & Low/moderate & 1.00 & & 1.00 & & & \\
\hline & & High & 0.64 & $(0.34-1.22)$ & 0.71 & $(0.36-1.42)$ & - & - \\
\hline & Male Fertility & Disagree & & & & & & \\
\hline & Entitlement (1) & Agree & - & - & - & - & - & - \\
\hline & Child-bearing perceptions (1) & Childlessness choice is wrong & - & - & - & - & - & - \\
\hline \multirow[t]{6}{*}{ Community } & Recreational facilities (1) & Inaccessible & & & & & & \\
\hline & & Accessible & - & - & - & - & - & - \\
\hline & Access to alcohol (1) & Low access & & & & & & \\
\hline & & High accessible & - & - & - & - & - & - \\
\hline & Social capital (6) & High & & & & & & \\
\hline & & Low & - & - & - & - & - & - \\
\hline \multirow[t]{6}{*}{ Partner Factors } & Age (1) & $18-29$ years & & & & & & \\
\hline & & $\geq 30$ years & - & - & - & - & - & - \\
\hline & Education (1) & Up to grade 9 & & & & & & \\
\hline & & Above grade 9 & - & - & - & - & - & - \\
\hline & Binge drinker(1) & No & 1.00 & & 1.00 & & 1.00 & \\
\hline & & Yes & 1.19 & $(0.68-2.09)$ & 1.41 & $(0.77-2.58)$ & $2.58^{*}$ & $(1.12-5.97)$ \\
\hline
\end{tabular}

${ }^{*} p<0.05 ;{ }^{* *} p<0.01 ;{ }^{* * *} p<0.001 ; \# \mathrm{p}<0.10$. -: Variable not included in multivariate analysis. 
Using the Level 3 outcome, bivariate analyses revealed that higher risk of an AEP was associated with current smoking $(\mathrm{OR}=3.60 ; 95 \% \quad \mathrm{CI}=1.46-8.88 ; \quad p<0.01)$; use of cannabis $(\mathrm{OR}=3.75 ; 95 \% \mathrm{CI}=1.29-10.94 ; p<0.05)$; alcohol use onset as a minor $(\mathrm{OR}=3.94 ; 95 \% \mathrm{CI}=1.93-8.03 ; p<0.001)$; and having a binge drinking partner $(\mathrm{OR}=3.59 ; 95 \% \mathrm{CI}=1.64-7.88 ; p<0.01$ ). Protective factors were being older (25-34 years versus $18-24$ years: $\quad \mathrm{OR}=0.37 ; 95 \% \mathrm{CI}=0.16-0.90 ; \quad p<0.05)$ and parity $(\mathrm{OR}=0.39 ; 95 \% \mathrm{CI}=0.19-0.80 ; p<0.01)$. Current smoking, initiation of alcohol consumption as a minor, and having a binge drinking partner retained significance in the multivariate analysis (Table 3 ).

\section{Discussion}

This first population-based survey of women's risk of an alcohol-exposed pregnancy in an urban (Gauteng) and rural (Western Cape) area of South Africa found that one in nine women in the urban area and one in five in the rural area were at risk of having an AEP by virtue of being current alcohol users, fertile, not pregnant and non-effective contraceptive users. Furthermore, the proportions of women who were at risk of an AEP on the basis of the strictest definition (Level 3: typically consuming five or more drinks per occasion) were $2.48 \%$ for the urban women and $8.50 \%$ for the rural women. Interestingly, these latter figures are very similar to the most recently reported FAS rates for an urban area in Gauteng of $1.9 \%$ (Viljoen et al., 2003) and a rural area in the Western Cape of between $6.8 \%$ and $8.9 \%$ (May et al., 2007). The proportion of the urban women who were at risk of an AEP of $2.48 \%$ is not dissimilar to that estimated for the United States of between $1 \%$ and $2 \%$ (Project Choices Research Group, 2002).

The rural women's disproportionate risk of an AEP and their demographic and alcohol consumption characteristics reflect their poor socio-economic conditions, as well as various social and historical influences including the dop system of part payment of farm workers with alcohol (London, 1999). Their elevated AEP risk is due mainly to their levels of alcohol use rather than their low or ineffective contraception, since their levels of contraceptive use did not differ significantly from those of their urban counterparts.

Inter-site similarities and differences in the factors associated with being at risk of an AEP were evident. Only cigarette smoking and low parity were risk factors that were common to women in both sites. However, the total combinations of factors associated with AEP risk give contrasting impressions of 'at risk' women in the two sites. For the urban site, the image that emerges of a woman at risk for an AEP (using criteria of at least three drinks per occasion, not using contraceptives and being fertile) is one of a smoker, with few or no children, minimal religious involvement, high selfesteem and high reported access to recreational facilities in her community; facilities which may include bars, taverns and shebeens in which alcohol is consumed. In contrast, a rural woman who is at risk of an AEP seems to be more likely to be impoverished and marginalised: a smoker with few or no children, low selfesteem and minimal education.

Regarding the less stringent outcome (being at risk of an AEP by virtue of using any alcohol, being fertile and ineffective contraception), it emerged that an urban woman who would qualify would be more likely than those who do not meet the criteria, to smoke cigarettes, be 'coloured' or 'white' (as opposed to 'black/ African') and to have good access to recreational facilities. For the rural women, those who qualified were more likely to smoke cigarettes, to have started drinking alcohol before 18 years, to have one or no children, to not be aware that drinking during pregnancy adversely affects the foetus, and to have a low level of education.

A most striking difference was that high self-esteem was associated with increased AEP risk for the urban women and decreased
AEP risk for the rural women. This finding for the rural women concurs with previous research linking low self-esteem with alcohol problems (Silverstone \& Salsali, 2003). The finding for the urban women can be explained in terms of an emerging phenomenon of increased alcohol consumption by women of higher SES in developing countries; increases which are attributed to changing gender roles, women's improved social and economic opportunities (Neve, Lemmens, \& Drop, 1996), and possibly, increased advertisements targeting women (European Centre for Monitoring Alcohol Marketing, 2008).

Most variables that we found to be associated with being at risk of an AEP are similar to those identified previously (e.g., Mengel et al., 2006; Project Choices Research Group, 2002). However, unlike other studies, we did not find mental and physical health perceptions to be significantly associated with being at risk of an AEP. Our result requires further exploration and may reflect unique features of women in South Africa.

In general, the factors associated with AEP risk in the present study are consistent with the maternal risk factors for FAS identified in previous studies in the Western and Northern Cape Provinces (May et al., 2005, 2008; Urban et al., 2008; Viljoen et al., 2002). However, parity was associated with lower risk of an AEP in this survey, but is usually associated with greater risk of having a child with an FASD. Arguably, a woman's likelihood of having an $\mathrm{AEP}$ is reduced, the more children she has, because having children exposes her to family planning and antenatal clinics from which she can learn about the harms of alcohol during pregnancy and access contraceptives.

\section{Limitations}

The first limitation of this study is its cross-sectional design which precludes conclusions about causality or the direction of observed associations. Second, being confined to women aged between 18 and 44 years, the study excluded adolescent females. Third, the validity of our assessment of ineffective contraceptive use cannot be established as it was not corroborated through medical records or other sources. Fourth, the use of self-report measures to assess alcohol consumption (and other behaviours) may have yielded under-reporting. However, our assurances to the participants of the confidentiality of their responses and our exclusion of names on the questionnaires increase our confidence in the findings. Moreover, investigators of studies of similar South African communities have indicated their impressions that women are not inclined to under-report their alcohol use (e.g., May et al., 2005). Fifth, although findings regarding the Level 3 outcome would provide the greatest insight into the risk of actually having a child with FAS, our relatively small sample size precluded the execution of multivariate analyses for the urban site. Use of larger community-based samples can make such analyses possible. Finally, the relatively low response rate among women in the formerly 'white' communities in the urban site suggests a need for caution in generalising the results to 'white' women beyond the urban study site.

\section{Implications}

The study has important implications for further research, clinical practice, prevention and policy interventions. Regarding future research, the similarity between our Level 3 (binge drinking) AEP risk rates and FAS prevalence rates in comparable locations in South Africa points to the potential value of community-based studies of this kind to estimate the likely FAS rates of communities; AEP risk rates may serve as a proxy measure for FAS rates. Community-based studies also have the advantage of avoiding the 
technical, ethical and financial challenges of more traditional active case ascertainment studies.

Similar research among females below 18 years is essential. Adolescent females are an important target group given that substance use disorders usually first occur in late adolescence and early adulthood (Kessler et al., 2007), and young females who are at high risk of having unplanned pregnancies are generally not inclined to access family planning services (Kaufman, de Wet, \& Stadler, 2003).

The findings suggest a need for location-specific targeted intervention approaches and provide pointers regarding the sub-groups of women who could potentially benefit from prevention programmes for reducing AEP risk. For women in the urban site, emphasis should be placed on targeting women who smoke cigarettes, have access to recreational facilities such as alcohol-serving establishments, high self-esteem, low religious involvement and fewer children. For rural farming communities, women who may benefit are those with minimal education, fewer children, current smokers, who initiated using alcohol at an early age (and are more likely to drink at problematic levels as adults; e.g. York, Welte, Hirsch, Hoffman, \& Barnes, 2004), and who are unaware that drinking alcohol during pregnancy has negative effects on the foetus.

Policy measures that are potentially effective in lowering population-level alcohol consumption in South Africa (such as reducing access to, and increasing restrictions on the marketing and distribution of alcohol products; Parry, 2005) should also have an impact on women's risk of AEP. Other potentially beneficial population strategies could include programmes to raise awareness among women of child-bearing age and the broader community, about alcohol's detrimental effects on the foetus. In rural farming communities in particular, programmes to reverse norms favouring alcohol use, promote contraceptive use, improve educational opportunities, and provide skills training may potentially reduce women's risk of AEPs, and in turn, the unprecedented rates of FAS and FASD.

The findings support the notion that all women of child-bearing age should be screened routinely (to identify their levels of contraceptive and alcohol use) in primary care, family planning and antenatal clinics (Floyd, Ebrahim, Tsai, O'Connor, \& Sokol, 2006). Pre-conception screening is particularly important since pregnancy recognition and first contact with antenatal services often occur late, after irreversible fetal damage may have occurred. Those who screen positive for AEP risk can benefit from programmes to reduce their drinking and/or increase their uptake of contraceptives such as brief advice and/or brief motivational counselling (e.g., Floyd et al., 2007) and referrals to substance use and family planning services, where necessary. Given our consistent finding of a strong association between smoking and risk of AEP, and the association of low birth weight with tobacco use alone (Jackson, Batiste, \& Rendall-Mkosi, 2007; Steyn, de Wet, Saloojee, Nel, \& Yach, 2006) or in combination with alcohol use (Jackson et al., 2007) during pregnancy, women of child-bearing age should also be screened routinely for and advised on smoking and other possible drugusing behaviours.

\section{Acknowledgements}

This publication was supported by Cooperative Agreement Number 1 U01 DD00044 from the Centers for Disease Control and Prevention (CDC). Its contents are solely the responsibility of the authors and do not necessarily represent the official views of the CDC. We would like to acknowledge the field coordination and supervision efforts of Nontobeko Jacobs, the Dopstop Association, Chantel Mazok, Molefe Pule, Nosimilo Zama, Owen Manda, Elmarie Nel and Bridget Kekana. Alta Hansen was responsible for entering the data sets. Rauf Sayed and Dr. Goedele Louwagie provided valuable statistical advice, and Dr Jo-Ann McLoughlin re-analysed the data to adjust for the clustering effect. Finally, we are grateful to Drs Jacquelyn Bertrand and Shahul Ebrahim for their valuable comments on the manuscript.

\section{References}

Babor, F. T., Higgins-Biddle, J. C., Saunders, J. B., \& Monteiro, M. G. (2001). The Alcoho Use Disorders Identification Test. Guidelines for use in primary care. Geneva: World Health Organization, Department of Mental Health and Substance Dependence.

Beksinska, M. E., Rees, V. H., Nkonyane, T., \& McIntyre, J. A. (1998). Compliance and use behaviour, an issue in injectable as well as oral contraceptive use? A study of injectable and oral contraceptive use in Johannesburg. British Journal of Family Planning, 24(1), 21-23.

European Centre for Monitoring Alcohol Marketing. (2008). Trends in alcohol marketing: Women the new market. The Netherlands: European Centre for Monitoring Alcohol Marketing.

Floyd, R. L., Ebrahim, S. H., Boyle, C. A., \& Gould, D. W. (1999). Observations from the CDC: preventing alcohol-exposed pregnancies among women of childbearing age: the necessity of a preconceptual approach. Journal of Women's Health and Gender-Based Medicine, 8, 733-736.

Floyd, R. L., Ebrahim, S., Tsai, J., O'Connor, M., \& Sokol, R. (2006). Strategies to reduce alcohol-exposed pregnancies. Maternal and Child Health Journal, 10, S149-S151.

Floyd, R. L., Sobell, M., Velasquez, M. M., Ingersoll, K., Nettleman, M., Sobell, L., et al . (2007). Preventing alcohol-exposed pregnancies: a randomized controlled trial. American Journal of Preventive Medicine, 32(1), 1-10.

Human Sciences Research Council (2006). Available from: http://www.hsrc.ac.za/ CCUP-GIS-1.phtml.

Idehen, E. E. (2001). The development and evaluation of a religiosity scale. IFE PsychologIA, 9(2), 58-69.

Jackson, D. J., Batiste, E., \& Rendall-Mkosi, K. (2007). Effect of smoking and alcohol use during pregnancy on the occurrence of low birthweight in a farming region in South Africa. Paediatric and Perinatal Epidemiology, 21(5), 432-440.

Jacobson, J. L., \& Jacobson, S. W. (1994). Prenatal exposure and neurobehavioural development: where is the threshold? Alcohol and Health Research World, 18(1) 30-36.

Kaufman, C. E., de Wet, T., \& Stadler, J. (2003). Adolescent pregnancy and parenthood in South Africa. Studies in Family Planning, 32, 147-160.

Kessler, R. C., Angermeyer, M., Anthony, J. C., De Graaf, R., Demyttenaere, K., Gasquet, I., et al. (2007). Lifetime prevalence and age-of-onset distributions of mental disorders in the World Health Organization's World Mental Health Survey Initiative. World Psychiatry, 6(3), 168-176.

King, G. (1997). The race concept in smoking: a review of the research on African Americans. Social Science E' Medicine, 45(7), 1075-1087.

London, L. (1999). The dop system, alcohol abuse and social control amongst farm workers in South Africa: a public health challenge. Social Science \& Medicine, 48 , 1407-1414.

Maier, S. E., \& West, J. R. (2001). Drinking patterns and alcohol-related birth defects Alcohol Research and Health, 25(3), 168-174.

Martin, K. S., Rogers, B. L., Cook, J. T., \& Joseph, H. M. (2004). Social capital is associated with decreased risk of hunger. Social Science $\mathcal{E}$ Medicine, 58 2645-2654.

May, P. A. (1995). A multiple-level comprehensive approach to the prevention of Fetal Alcohol Syndrome (FAS) and other Alcohol-Related Birth Defects (ARBD). International Journal of the Addictions, 30(12), 1549-1602.

May, P. A., Brooke, L. E., Gossage, J. P., Croxford, J., Adnams, C. Jones, K. L, et al (2000). Epidemiology of Fetal Alcohol Syndrome in a South African community in the Western Cape Province. American Journal of Public Health, 90(12) 1905-1912.

May, P. A., Gossage, J. P., Brooke, L. E., Snell, C. L., Marais, A.-S., Hendricks, L. S., et al (2005). Maternal risk factors for Fetal Alcohol Syndrome in the Western Cape Province of South Africa: a Population-Based Study. American Journal of Public Health, 95(7), 1190-1199.

May, P. A., Gossage, J. P., Marais, A.-S., Adnams, C. M., Hoyme, H. E., Jones, K. L., et al (2007). The epidemiology of Fetal Alcohol Syndrome and partial FAS in a South African community. Drug and Alcohol Dependence, 88, 259-271.

May, P. A., Gossage, J. P., Marais, A.-S., Hendricks, L. S., Snell, C. L., Tabachnick, B. G., et al. (2008). Maternal risk factors for Fetal Alcohol Syndrome and partial Feta Alcohol Syndrome in South Africa: a third study. Alcoholism: Clinical and Experimental Research, 32(5), 738-753.

Mengel, M. B., Searight, H. R., \& Cook, K. (2006). Preventing alcohol-exposed pregnancies. Journal of the American Board of Family Medicine, 19(5), 494-505.

Neve, R. J. M., Lemmens, P. H., \& Drop, M. J. (1996). Gender differences in alcohol use and alcohol problems: mediation by social roles and gender-role attitudes. Substance Use E' Misuse, 32, 1439-1459.

Palmer, C. (1985). Fetal alcohol effects - incidence and understanding in the Cape. South African Medical Journal, 68(11), 779-780.

Parry, C. D. H. (2005). A review of policy-relevant strategies and interventions to address the burden of alcohol on individuals and society in South Africa. South African Psychiatry Review, 8(1), 20-24. 
Parry, C. D. H., Plüddemann, A., Steyn, K., Bradshaw, D., Norman, R., \& Laubscher, R. (2005). Alcohol use in South Africa: findings from the first demographic and health survey (1998). Journal of Studies on Alcohol, 66, 91-97.

Project Choices Research Group. (2002). Alcohol-exposed pregnancy: characteristics associated with risk. American Journal of Public Health, 23(3), 166-173.

Rosenberg, M. (1965). Society and the adolescent self-image. Princeton, NJ: Prince University Press.

Sampson, P. D., Streissguth, A. P., Bookstein, F. L., \& Barr, H. M. (2000). On categorizations in analyses of alcohol teratogenesis. Environmental Health Perspectives, 108(Suppl. 3), 421-428.

Silverstone, P. H., \& Salsali, M. (2003). Low self-esteem and psychiatric patients: part I - the relationship between low self-esteem and psychiatric diagnosis. Annals of General Hospital Psychiatry, 2(2). doi:10.1186/1475-2832-2-2.

Statistics South Africa. (2003). Census 2001: Census in brief. Pretoria: Statistics South Africa.

Stephenson, R., Baschieri, A., Clements, S., Hennink, M., \& Madise, N. (2007) Contextual influences on modern contraceptive use in sub-Saharan Africa. American Journal of Public Health, 97(7), 1233-1240.

Stewart, A. L., Hays, R. D., \& Ware, Jr. J. E. (1988). The MOS Short-Form General Health Survey: reliability and validity in a patient population. Medical Care, 26, 724-735.

Steyn, K., de Wet, T., Saloojee, Y., Nel, H., \& Yach, D. (2006). The influence of maternal cigarette smoking, snuff use and passive smoking on pregnancy outcomes: the Birth To Ten Study. Paediatric and Perinatal Epidemiology, 20(2), 90-99.

Stratton, K., Howe, C., \& Battaglis, F. (Eds.) (1996). Institute of medicine. Fetal Alcoho Syndrome: Diagnosis, epidemiology, prevention, and treatment. Washington, DC: National Academy Press.

te Water Naude, J., London, L., Pitt, B., \& Mahomed, C. (1998). The 'dop' system around Stellenbosch - results of a farm survey. South African Medical Journal, 88, 1102-1105.
Urban-Econ. (2006). West coast district: Poverty alleviation strategy. Cape Town: Urban-Econ.

Urban, M., Chersich, M. F., Fourie, L.-A., Chetty, C., Olivier, L., \& Viljoen, D. (2008). Fetal Alcohol Syndrome among Grade 1 schoolchildren in Northern Cape Province: prevalence and risk factors. South African Medical Journal, 98(11), 877-882.

Viljoen, D. L., Craig, P., Hymbaugh, K., Boyle, C., \& Blount, S. (2003). Fetal Alcohol Syndrome - South Africa. 2001. Morbidity and Mortality Weekly Report, 52(28), 660-662.

Viljoen, D. L., Croxford, J., Gossage, J. P., Kodituwakku, P. W., \& May, P. A. (2002). Characteristics of mothers of children with Fetal Alcohol Syndrome in the Western Cape province of South Africa: a case control study. Journal of Studies on Alcohol, 63, 6-17.

Viljoen, D. L., Gossage, J. P., Brooke, L., Adnams, C. M., Jones, K. L., Robinson, L. K., et al. (2005). Fetal Alcohol Syndrome Epidemiology in a South African community: a second study of a very high prevalence area. Journal of Studies on Alcohol, 66(5), 593-604.

West Coast District Municipality. (2009). Wikipedia online. http://www.wikipedia. org. Accessed 12.02.09.

Wood, K., \& Jewkes, R. (2006). Blood blockages and scolding nurses: barriers to adolescent contraceptive use in South Africa. Reproductive Health Matters, 14(27), 109-118.

World Health Organization (WHO). (2004). Global status report on alcohol 2004. Geneva: WHO, Department of Mental Health and Substance Abuse.

York, J. L., Welte, J., Hirsch, J., Hoffman, J. H., \& Barnes, G. (2004). Association of age at first drink with current alcohol drinking variables in a national general population sample. Alcoholism: Clinical and Experimental Research, 28(9), 1379-1387. 